\title{
POLÍTICAS PÚBLICAS EM EMPREGABILIDADE: ELEMENTOS PARA UMA CRÍTICA
}

\section{PUBLIC POLICY IN EMPLOYABILITY: ELEMENTS FOR A CRITICAL ANALYSIS}

\section{Antônio Gabriel S. Martins ${ }^{1}$}

\section{RESUMO}

Diante das alarmantes e crescentes taxas de desemprego atuais, vemos os Estados capitalistas alterarem suas políticas de combate ao desemprego para políticas de empregabilidade. Tais mudanças, contudo, antes de serem analisadas como atualizações políticas, como adaptações a novos tempos, devem ser analisadas considerando algumas especificidades como: (a) o que é a empregabilidade, (b) quais as alterações que provocam tamanho aumento no desemprego e, principalmente, (c) como se articulam ambas. Visando contribuir para uma análise crítica das políticas de empregabilidade, o presente artigo aponta para elementos que devem ser considerados para a discussão do caráter e função das políticas públicas em empregabilidade.

PALAVRAS-CHAVE: empregabilidade - desemprego - capitalismo

\section{ABSTRACT}

Faced with the alarming and increasing rates of current unemployment, we see the capitalist States to change their policies to combat unemployment on employability policy. Such changes, however, before being analyzed as policy updates, as adaptations to changing times, should be analyzed considering some specifics like: (a) what is employability, (b) which social changes that cause the increase in unemployment and, especially, (c) how to articulate both. To contribute to a critical analysis of employability policies, this article points to factors to be considered for the discussion of the nature and social function of public policies on employability. 
KEYWORDS: Employability - Unemployment - Capitalism.

\section{INTRODUÇÃO}

Dentre as alterações ocorridas na sociedade capitalista nas últimas quatro décadas, talvez o que mais claramente se apresente enquanto problema social de emergente necessidade de solução seja o crescente desemprego. Chamam tanto à atenção as crescentes taxas de desemprego, que levam muitos autores a apontarem para o surgimento dos "inimpregáveis" e outros afirmarem que o desemprego é estrutural.

Mais que o meio acadêmico, a grande mídia ou o Estado, é a classe trabalhadora quem sente na pele as conseqüências do que são mais que estatísticas. Em meio a este cenário quase apocalíptico apresentado e vivenciado pela classe que tem de vender sua força de trabalho para reproduzir sua vida, os Estados capitalistas apresentam alterações em suas políticas de emprego. O pleno emprego e mesmo a luta pela redução do desemprego são abandonados paulatinamente pelos Estados capitalistas e em seu lugar são inseridas uma série de ações políticas (e ideológicas) de combate ao desemprego, chamadas, genericamente, de empregabilidade.

Quando nos atentamos ao quadro político e educacional da forma como o emprego é combatido na sociedade capitalista em sua atual fase, nos deparamos com as típicas ações estatais monopolistas apontadas por Netto (1996): fragmentação e particialização das "questões sociais". Com o combate ao desemprego, o direito ao emprego, portanto, perdendo espaço às políticas de empregabilidade, as políticas públicas de emprego dos Estados capitalistas são paulatinamente substituídas por políticas de auto-responsabilização dos desempregados e de redução de custos de formação da força de trabalho.

A seguir, dissertarei, sinteticamente, sobre esta mirabolante solução individual para um problema social tão próprio da transitória sociedade capitalista para, por fim, inseri-la nas discussões acerca da estrutura social sobre a qual 
emerge e se sustenta, visando apontar elementos que ajudem a esclarecer as causas do crescente desemprego atualmente e o fracasso inerente das políticas públicas de combate ao desemprego através de programas de empregabilidade.

\section{EMPREGO, DESEMPREGO E EMPREGABILIDADE}

Diante das crescentes taxas mundiais de desemprego, chamam à atenção as alterações nas políticas públicas de combate a este efeito próprio do modo de produção capitalista. As políticas de combate ao desemprego, muito impregnadas pela lógica de combate a "desvios" e "desfunções" da sociabilidade capitalista, adaptam-se aos tempos de "desemprego estrutural", ou "crônico", ao abandonarem, paulatinamente, o combate ao desemprego, em vistas de sua "eliminação", tal como o fizeram os Estados de Bem-Estar Social, e apresentarem políticas públicas de empregabilidade. Mas, o que é, exatamente, empregabilidade e quais as conseqüência de políticas deste caráter?

Empregabilidade diz respeito, segundo Hirata (1997, p. 333), à passagem da situação de desemprego para a de emprego, ou como melhor define Shiroma (1998, p. 01) acerca desta mesma afirmação, Hirata define a empregabilidade como "a probabilidade de saída do desemprego ou como a "capacidade de obter um emprego"'.

Para Bueno (1996, apud Shiroma, p. 01) a empregabilidade é definida como a "aptidão dos trabalhadores em conquistar um emprego e mantê-lo todos os dias prosperando numa sociedade sem empregos". Chegamos aqui em um elemento novo, outrora relegado por Hirata: a manutenção do emprego. O que antes se apresentava como um problema de eminente impossibilidade de produção da vida ao trabalhador sem emprego se apresenta agora como um fantasma ao trabalhador empregado, que compreende que seu emprego já não é mais o estável emprego da sociedade fordista, mas uma frágil condição em uma sociedade de desemprego estrutural. 
Neste sentido, Musa (apud CASALI, 1997, p. 10) argumenta que "hoje o empresário já não pode mais garantir emprego, cabe-lhe proporcionar [, então,] a empregabilidade, isto é, a capacitar seus empregados para novas necessidades [...] internas e externas que surgirão no futuro". Aqui se retira do Estado o dever de promotor das políticas de emprego e mesmo suas atribuições de regulador e ordenador da ordem capitalista mediante o combate às mazelas deste mesmo modo de produção na chamada "questão social". Desloca-se, assim, paulatinamente, o combate político ao desemprego para uma série de justificações e ações por parte de cada trabalhador individualmente, como apresentarei adiante.

Menegasso (1999) afirma que "o termo empregabilidade compreende tanto a capacidade de cada pessoa de ser dona de seu próprio destino, dando significado a sua vida, quanto à capacidade de prover os meios necessários para sua sobrevivência", esquecendo-se a autora, porém, que o desemprego é imposto aos trabalhadores na sociedade capitalista contemporânea enquanto classe e não, necessariamente, enquanto indivíduos e que vencer o desemprego nestes termos significa vencer outros desempregados na disputa por um emprego, semelhante a uma dança das cadeiras, em que para um vencer, muitos têm de perder.

Segundo Hirata (apud TEIXEIRA, 2003) argumenta, é a mutabilidade do mercado de trabalho hodierno que impõe um ritmo de constante desenvolvimento de habilidades cognitivas e reflexivas, além das capacitações de nível técnico para que o trabalhador se torne e/ou continue "empregável". O que nos aparece até aqui é uma incrível e fértil rede de ações de todos os tipos de justificação das causas do desemprego no indivíduo desempregado, que deve buscar uma melhor "qualificação" para empregar-se em um paranóico jogo de competitividade com outros desempregados ou potenciais desempregados.

Segundo Teixeira (2003)

No conceito de "empregabilidade está implícita a tendência de eximir o Estado do seu "dever" em relação ao direito do cidadão ao trabalho, de caráter público e político, e repassar tal dever aos indivíduos, considerados isoladamente, tornando esse dever, deste modo, uma questão privada, pessoal. Assim, a "empregabilidade" significa o "dever" de cada indivíduo (que desaparece como cidadão, já que, no conceito de cidadania, há a dimensão do coletivo, do público) de encontrar seu próprio trabalho no mercado capitalista (p. 07). 
Gentili (1998 apud ALVES, 2007) vai além e afirma que

a empregabilidade se incorpora ao senso comum como significado que contribui a estruturar, orientar e definir as opções (ou a falta de opções) dos indivíduos no campo educacional e no mercado de trabalho, tornando-se também "a" referência norteadora, o "deve ser" dos programas de formação profissional e, inclusive, das próprias políticas educacionais (p. 248).

Segundo o próprio Ministério do Trabalho (MTb) brasileiro, onde o conceito começou a ser veiculado em meados dos anos 90 (SHIROMA, 1998, p. 02), "a empregabilidade deve ser entendida como capacidade não só de se obter um emprego, mas sobretudo de se manter em um mercado de trabalho em constante mutação" (BRASIL/MTb, 1995, p 09.).

É importante lembrar que para o MTb, a Educação Profissional é considerada complementar à educação básica regular e deve ter como objetivo a empregabilidade (MEC/MTb apud SHIROMA, 1998, p. 02). Segundo a autora (1998),

- a empregabilidade envolve três fatores interrelacionados: investimentos geradores de trabalho, serviços de intermediação eficientes e educação contínua do trabalhador.

- esses fatores decorrem da crescente globalização e competitividade da economia. Processos de modernização e reestruturação (sic) começam em setores de ponta, mas rebatem todo tipo de empresas - até no mercado informal.

- começa a nascer, desse processo, a exigência de um novo perfil de trabalhador, capaz não apenas de "fazer", mas de "pensar" e "aprender" continuamente (p. 02).

O perfil almejado e anunciado nos documento do MTb depende, sobretudo, de relacionar a Educação Profissional com as outras esferas educacionais formais brasileiras. Shiroma (1998) ressalta ainda que esta vinculação produz, como elemento principal, "uma educação profissional permanente, mas sempre com começo, meio e fim - ou seja, focalizado no mercado, garantindo ao trabalhador chances de entrada e saída no processo de formação, ao longo de sua vida profissional" (p. 03). 
Dessa forma, a autora ressalta que a cooperação entre MTb e MEC anunciou a priorização de três projetos de grande alcance, a saber:

- a implementação de um Plano Nacional de Educação Profissional;

- a criação de uma rede de Centros de Educação Profissional e

- a formulação de uma política para o Ensino Médio

E constata que

[...] na política para o Ensino Médio, já formulada, a empregabilidade que, a princípio, era meta somente da Educação Profissional no âmbito do PLANFOR, ultrapassa a fronteira e invade os documentos do MEC. O parecer de Guiomar Namo de Mello sobre as Diretrizes Curriculares do Ensino Médio se reportou à "valorização da educação como estratégia de melhoria de vida e empregabilidade" (1998, p. 08).

Mas os projetos iniciados há mais de uma década tiveram quais impactos? Quais foram as conseqüências das políticas para a empregabilidade?

Segundo o DIEESE (2010), entre 1998 e julho 2010, aproximadamente $60,01 \%$ das mulheres empregadas possuíam carteira assinada e $69,08 \%$ dos homens que trabalham estão legalmente registrados, sendo a média atual $68,04 \%$ dos trabalhadores registrados legalmente como trabalhadores assalariados.

O tempo médio de dispêndio para encontrar um emprego nas regiões metropolitanas brasileiras no mês de julho de 2010 era de oito meses, sendo a média dos homens inferior à média das mulheres (sete meses, em média, leva um homem para encontrar um emprego e nove levam as mulheres), e sendo a média na região metropolitana superior a um ano de desemprego (15 meses, em média), conforme aponta o DIEESE (2010).

Entre 1998 e julho de 2010, em média 30,2\% das mulheres estavam desempregadas e $26,1 \%$ dos homens. Mais especificamente em julho de 2010 , o DIEESE apresentou o dado de que, nas regiões metropolitanas brasileiras, em média $12,60 \%$ das pessoas em idade de trabalho estavam desempregadas DIEESE (2010).

Todos estes dados tornam-se mais expressivos quando analisamos a questão do emprego no país em comparação com a composição do emprego com o 
restante do mundo. Para melhor inserirmos a particularidade do emprego no Brasil em relação à totalidade do emprego no mundo, a seguir discutirei, brevemente, a divisão internacional do trabalho e o toyotismo.

\section{DIVISÃO INTERNACIONAL DO TRABALHO E TOYTOTISMO}

As políticas econômicas e sociais brasileiras a partir dos anos 1980 são frutos do que Pochman (2009) chama de Terceira Divisão Internacional do Trabalho. Segundo o autor, a partir dos anos sessenta do século passado começa a maturar uma nova divisão internacional do trabalho, fruto da crise (estrutural) capitalista e do fim da URSS.

Com o monopólio político, econômico e militar americano a partir de 1980 e com a insustentável crise estrutural capitalista, a produção industrial do planeta que iniciou no sistema sóciometabólico capitalista restrita a alguns poucos países e, posteriormente, se expandiu a uma pequena parcela de países da periferia do sistema - chamados por Pochman (2009) de semiperiferia - passou a ser parcelada e deslocada para os países de fora do centro do sistema. Com isso, muitos países deixaram de ser exclusivos produtores de bens primários e passaram a disputar com outros países subdesenvolvidos a chance de atrair parte das indústrias do centro capitalista.

A mudança das indústrias capitalistas para fora dos países do centro do capitalismo se deu motivada pela possibilidade de redução de custos e de compensação da cada dia mais alarmante taxa decrescente de lucro. Saindo dos países centrais, as indústrias capitalistas fogem dos direitos sociais antes conquistados pelos trabalhadores desses países e compensam seu proporcionalmente reduzido lucro com práticas de produção já superadas pelos países centrais, baseadas na intensificação do trabalho e protegidas por mercados com leis trabalhistas frouxas.

A nova divisão internacional do trabalho deve-se a muitos fatores articulados entre si, imbricados, dos quais tem destacada importância o novo padrão 
de acumulação desenvolvido a partir de 1950 no Japão e difundido no mundo a partir da crise estrutural capitalista, em 1970.

O novo padrão de acumulação que emerge nos anos 70 e dá sustentação para a nova divisão do trabalho configurada a partir de 1980, se gesta na década de 1960. A partir desse período observa-se uma crescente crise para a manutenção do modo de acumulação taylorista-fordista e do Estado de Bem-Estar Social. Montaño (1999) afirma que o aumento de direitos da classe trabalhadora constitui um problema de direção à classe capitalista, além de serem excessivamente dispendiosos ao Estado. O custo elevado para a manutenção desses direitos gera forte crise fiscal ao Estado de Bem-Estar social, o que leva o autor a argumentar que o desmonte desse modelo de Estado dá-se por dois motivos: (a) alto custo para a manutenção dos direitos sociais e (b) risco, real ou potencial, de maiores avanços a persistir a "lógica democrática" deste Estado.

Para Antunes (2003), a chamada "crise do fordismo" - como comumente se denomina o princípio da crise estrutural do capital - manifesta-se a partir do princípio da década de 70 do século XX. Para o autor (pp. 29-30), esta crise é manifestada pela conjugação dos seguintes elementos: (a) acentuação da queda da taxa de lucro dada pelo aumento dos salários; (b) incapacidade do modo de acumulação taylorista-fordista em se adaptar à retração do consumo devido ao crescimento do desemprego; (c) "hipertrofia da esfera financeira, que ganhava relativa autonomia frente aos capitais produtivos"; (d) concentração de capital através de fusões e do aumento de oligopólios e monopólios; (e) crise dos mecanismos de funcionamento do Estado Keynesiano, que acarretou na "crise fiscal do Estado capitalista e [n]a necessidade de retração dos gastos públicos e sua transferência para o capital privado", dando início às (f) privatizações e (g) flexibilização dos mercados e da força de trabalho.

Estas contradições que em princípio pareciam colocar o capitalismo em xeque. Dentro das grandes organizações capitalistas, entretanto, já há um movimento que busca novas formas e práticas para reproduzir o capital. Movimento este conhecido hoje como Reestruturação Produtiva. A Reestruturação Produtiva 
implica a flexibilização do trabalho e do capital para a manutenção da extração da mais-valia e conseqüente valorização do valor.

O princípio da flexibilização inicia com o que se chama de "modelo japonês de produção". Inicialmente concebido na Toyota Motor Company, na década de 1950, o toyotismo, outra designação do chamado "modelo japonês", surge como um amontoado de práticas que buscavam contornar a grave crise econômica que assolou o Japão após a quase completa destruição daquele país ao fim da Segunda Guerra Mundial.

Aliando os modelos de produção em massa do taylorismo-fordismo a características locais, como o potencial de pesquisa da indústria japonesa, o engenheiro Taiichi Ohno desenvolve uma série de métodos e uma nova concepção de produção, também chamada de produção flexível, cujos elementos que a caracterizam e a constituem não se limitam a processos de trabalho, mas também a mecanismos institucionais e o sindicato-de-empresa (OLIVEIRA, 2004).

O engenheiro conclui que:

Há duas maneiras de aumentar a produtividade: uma pelo aumento constante das quantidades produzidas, a outra pela diminuição constante dos trabalhadores. A Toyota escolheu a segunda, que é menos popular, mas que significaria repensar em todos os seus detalhes a organização do trabalho (TAIICHI OHNO apud OLIVEIRA, 2004: p. 23).

Operando com um custo muito reduzido, a Toyota logo se torna a terceira colocada mundial em vendas de automóveis. Com a importação das técnicas de gestão americanas, como as que deram origem ao kanban, a Toyota passa a exigir de seus fornecedores a redução de custos para baratear toda sua cadeia produtiva, o que acaba por generalizar o "toyotismo" como modo de acumulação no Japão (CORIAT apud OLIVEIRA, 2004).

Tal barateamento dá-se pela utilização de práticas diversas no toyotismo, sendo uma das principais delas a terceirização. Nesta prática, os trabalhadores de certas atividades são subcontratados por período, e não por funções, a serem executadas em diversas outras empresas, conforme a necessidade de mão-de-obra. 
Neste período, ocorreu um significativo número de falências e fusões de grandes organizações no Japão e no mundo, aumentando a concentração de riquezas gigantescas com a formação de grandes monopólios e oligopólios nipônicos. Tal concentração acentua-se nos países europeus quando a crise de arrecadação do Estado Keynesiano leva muitos estados nacionais a privatizarem empresas públicas, ampliando o controle econômico das grandes empresas sobre estes Estados.

Neste contexto, Montaño (2002) afirma que, a fim de contornar todos os problemas de arrecadação do Estado, as grandes organizações passam a controlar o avanço dos direitos trabalhistas e a pressionar por reformas nos Estados nacionais. Dessa forma, muitos Estados de países do capitalismo central, a fim de reduzir suas despesas, privatizaram um grande número de empresas públicas, retirando muitos serviços da "incompetência e ingerência" do Estado, transferindo assim, questões sociais para a sociedade civil e a para a lógica concorrencial, criando novos nichos de mercado com a "venda de direitos" outrora assegurados pelo Estado.

Aliada à crise do Estado Keynesiano e posterior a reforma do Estado, a generalização do toyotismo permitiu um método de gestão capaz de manter as relações de extração de mais-valia e rentabilidade em detrimento das taxas decrescentes de lucros. Assim, flexibilizações, terceirizações e crescimento de trabalhadores periféricos nas grandes empresas, com empregos instáveis e sem direitos assegurados, são a contrapartida da "responsabilidade social" apregoada pelas grandes empresas que terceirizam suas "atividades-meio" do, também chamado, padrão flexível de acumulação.

As bases deste padrão de acumulação estão aqui claramente expostas: redução dos postos de trabalho, sem redução da produção mediante a intensificação da exploração do trabalho via novos modelos de gestão. Ribas (1999, p. 80) afirma que o toyotismo é um dos determinantes de toda a política de uma sociedade organizada para a valorização do capital e que parece "[...] só ter triunfado tendo como pressuposto a negação de toda a capacidade criativa, de todo o espírito, de todo o engenho humano que não esteja a serviço da produção". 
As conseqüências destas políticas são aterradoras. Dos problemas físicos, emocionais e psicológicos decorrentes da intensificação do trabalho denunciada por um sem-número de autores às questões morais, chama a atenção o desemprego, hoje generalizado.

Diferentemente do que os autores posicionados em defesa da empregabilidade como resolução do desemprego afirmam, é a partir deste novo cenário que se desenvolve a empregabilidade. Segundo Alves (2007)

\begin{abstract}
O conceito de empregabilidade representa, em si, os paradoxos do toyotismo, seja naquilo que ele representa de nova "verdade tecnológica" (Marcuse), com sua exigências de novas qualificações para o mundo do trabalho assalariado, seja naquilo que representa de uma incapacidade em realizar uma hegemonia social ampla [...]. O conceito opera com clareza ideológica as contradições da mundialização do capital, um sistema mundial de produção de mercadorias centrado na lógica da financeirização e da "produção enxuta", totalmente avesso às políticas de pleno emprego e geradora de desemprego e exclusão social. É por isso que a mundialização do capital tende a disseminar como eixo estruturador de sua política de formação profissional o conceito de empregabilidade, que aparece como relativo consenso nos discursos neoliberais ou sociais-democratas, como requisito básico para superar a crise do desemprego (p. 250).
\end{abstract}

A generalização do toyotismo é um dos elementos decisivos a uma divisão internacional do trabalho - sombria aos trabalhadores de todos os países. Aos países de fora do centro do capitalismo competem os empregos referentes ao trabalho braçal, à montagem de equipamentos, à produção propriamente dita; aos países centrais, compete o planejamento de sua produção transnacional, ao desenvolvimento intelectual de suas produções (POCHMAN, 2009).

Neste cenário, algumas poucas grandes corporações possuem o controle da produção de quase todos os setores produtivos2, terceirizando as atividades de trabalho manual, levadas aos países de fora do centro do capitalismo. A ida das atividades manuais para os países de fora do centro capitalista são motivadas, como disse anteriormente, pela redução drástica nos custos de produção.

Com isso, os países periféricos e semiperiféricos competem entre si em verdadeiros "feirões" de captação de produção industrial, cujas vantagens competitivas são, por conseqüência, as possibilidades de redução de custo, com grande destaque às possibilidades de redução de custo com mão de obra. A atração se dá pela redução de direitos, desregulamentação de leis trabalhistas e 
constrangimentos sindicais, o que possibilita ainda maior intensificação do trabalho (ANTUNES, 2003) e avanço de práticas de extração de mais-valia absoluta.

Nos países centrais, a saída das indústrias, levadas aos países periféricos e semiperiféricos com leis trabalhistas mais frouxas e Estados submissos, a crise estrutural também se faz perceber na crise empregos. Em 2009 existiam mais de 40 milhões de desempregados nos países do centro do capitalismo, sendo 20 milhões desses na Europa (MÉSZÁROS, 2007, p. 143).

Se por um lado os países pobres - mesmo os países da antiga URRS são reféns do imperativo de redução de direitos e da intensificação do trabalho a fim de não perderem os empregos terceirizados e precários destinados pelos países do capitalismo central, os últimos também sofrem com redução estrutural no número de postos de trabalho e intensificação do trabalho. Segundo Mészáros (2002, p. 1005)

\begin{abstract}
O problema não mais se restringe à difícil situação dos trabalhadores nãoqualificados, mas atinge também um grande número de trabalhadores altamente qualificados, que agora disputam, somando-se ao estoque anterior de desempregados, os escassos - e cada vez mais raros empregos disponíveis. Da mesma forma, a tendência da amputação "racionalizadora" não está mais limitada aos "ramos periféricos de uma indústria obsoleta", mas abarca alguns dos mais desenvolvidos e modernizados setores da produção - da indústria naval e aeronáutica à eletrônica, e da indústria mecânica à tecnologia espacial.
\end{abstract}

Portanto, não estamos mais diante dos subprodutos "normais" e voluntariamente aceitos do "crescimento e desenvolvimento", mas de seu movimento em direção a um colapso; nem tampouco diante de problemas periféricos dos "bolsões de subdesenvolvimento", mas diante de uma contradição fundamental do modo de produção capitalista como um todo, que transforma até mesmo as últimas conquistas do "desenvolvimento", da "racionalização" e da "modernização" em fardos paralisantes de subdesenvolvimento crônico. E o mais importante de tudo é que quem sofre as conseqüências dessa situação não é mais a multidão socialmente impotente, apática e fragmentada das pessoas "desprivilegiadas", mas todas as categorias de trabalhadores qualificados e não-qualificados: ou seja, obviamente, a totalidade da força de trabalho da sociedade.

Chegamos aqui a elemento central de discussão de emprego e desemprego, como formas de produção da vida: a impossibilidade de produção humana da vida dentro da sociedade capitalista, evidenciada pelo máximo desenvolvimento deste modo de produção a partir de sua crise estrutural.

Segundo Mészáros (2005) 
a crise global da acumulação de capital na era da globalização avançada cria algumas grandes dificuldades novas, ao invés de resolver aquelas há muito contestadas iniqüidades do sistema, como os "otimistas" porta-vozes da "globalização" não querem fazer-nos acreditar. Pois as margens da viabilidade produtiva do capital estão a diminuir (daí o impulso para a maisvalia absoluta), apesar de todos os esforços dos Estados capitalistas individualmente ou em conjunto, como nos encontros do G7/G8 - para expandir, ou pelo menos manter firmes, as margens produtivas do sistema. $\mathrm{Na}$ realidade só pode haver um caminho para tentar alargar as margens contraídas da acumulação de capital: a expensas do trabalho. Isto é uma estratégia promovida ativamente pelo Estado - na verdade, devido a esta necessidade, o papel intervencionista do Estado nunca foi tão grande [...] como neste nosso tempo, apesar de toda a mitologia neoliberal em contrário - e a estratégia é objetivamente apoiada no nosso tempo pela tendência para a equalização declinante da taxa de exploração diferencial. No fim, contudo, a estratégia agora perseguida está votada ao fracasso, desde que o movimento dos trabalhadores tenha êxito em rearticular radicalmente suas próprias estratégias e formas de organização, orientando-as rumo à criação de um movimento de massas genuíno, a fim de fazer face ao desafio histórico. Pois nem mesmo os teóricos mais "otimistas" do FMl e dos outros generosamente financiados órgãos de apologia do capital conseguiram até agora inventar, nem é provável que o consigam no futuro, um dispositivo pelo qual seria possível espremer para fora o exigido poder de compra sempre crescente e a correspondente acumulação de capital das cada vez piores condições econômicas e dos "pacotes de salários precarizados" da força de trabalho.

\section{CONSIDERAÇÃO FINAIS}

A busca pela resolução do desemprego mediante políticas de empregabilidade é uma busca pelo impossível. Quando há a proposição de desenvolvimento de habilidades individuais para manutenção ou conquista de emprego, se vela a realidade social do desemprego e se culpa o indivíduo a buscar um treinamento para um emprego que ainda nem existe para ele. Onera-se o desempregado psicológica, emocional e financeiramente ao exigir que o trabalhador desempregado faça treinamento para estar apto a um emprego que ele não tem, apenas a ele concorre. Ao se teorizar por políticas públicas, entretanto, esbarra-se nas estruturas do sistema capitalista e coloca-se em xeque a sociedade que, desde seus primórdios, desenvolveu o emprego.

A maturidade do sistema capitalista, já completamente desenvolvido, como argumenta Mészáros ao longo de sua obra, entra em colapso e, de suas 
contradições internas, leva o desemprego a um nível crítico, insolúvel e em crescente tendência.

Mészáros (2007, p. 145) argumenta que

[...] alcançamos um ponto de desenvolvimento histórico em que o desemprego se coloca como um traço dominante do sistema capitalista como um todo. Em sua nova modalidade, constitui uma malha de interrelações e interdeterminações pelas quais hoje se torna impossível encontrar remédios e soluções parciais para o problema do desemprego em áreas restritas, em agudo contraste com as décadas pós-guerra de desenvolvimento em alguns países privilegiados, nos quais os liberais podiam falar sobre pleno emprego em uma sociedade livre (grifos do autor).

\section{O autor ressalta que o desemprego é hoje uma conseqüência do próprio} desenvolvimento capitalista e que a maturidade do sistema "culmina com a geração de um número cada vez maior de seres humanos supérfluos a seu maquinário de produção" (p. 146). Segundo o filósofo:

Quando o capital alcança esse estágio de desenvolvimento, não tem como tratar as causas de sua crise estrutural; pode apenas perder tempo com esforços e manifestações superficiais. Por conseguinte, uma vez que o capital "não pode assegurar a existência de seu escravo", as "personificações do capital" [...] procuram resolver o problema encurtando até mesmo os limitados benefícios concedidos ao trabalho na forma do "Estado de bem-estar social" - durante o período pós-guerra de expansão intacta do capital - por meio de sua impugnação e abolição. Assim, nos Estados Unidos, os desempregados são obrigados a submeter-se aos ditames do workfaire ${ }^{3}$ para receber algum benefício. E, tipicamente, na Inglaterra o governo de um partido que já foi considerado socialista procura agora instituir a mesma mudança, do [...] welfare para o workfaire. Por conseguinte, quando $o$ artigo de oito colunas de um jornal inglês liberal [...] anuncia: "Desocupados são avisados: entrem no Exército ou perderão o benefício", oferece uma amostra das medidas que aguardam ser implementadas para a juventude desempregada. Isso, mais uma vez, ao lado dos outros aspectos do nosso problema [...], sublima o fato de que a "globalização" agora plenamente concluída do desemprego e da precarização não pode ser solucionada sem a suplantação do próprio sistema do capital. Há não tantos anos, antecipou-se confiantemente que todos os males sociais conhecidos, até mesmo nas partes mais "subdesenvolvidas" do mundo, seriam superados pela "modernização" universal, em conformidade com o modelo norte-americano. Entretanto, caracteristicamente, enfrentamos hoje o posto diametral do róseo quadro projetado. Pois as condições que antes limitavam, nos contos de fada da "teoria desenvolvimentista" e da sabedoria governamental, às dificuldades supostamente temporárias do "subdesenvolvimento" estão agora se tornando claramente visíveis mesmo nos países capitalisticamente mais avançados (2007, p. 146) 
Neste sentido é absolutamente absurdo falarmos hoje crermos na efetividade das políticas em empregabilidade como possíveis de superar o desemprego. As conseqüências dos programas de empregabilidade não são de redução do desemprego, mas de, entre outras conseqüências, justificação para intensificação do trabalho, aumento da jornada de trabalho, constrangimento ao sindicalismo sob o fantasma do desemprego, redução dos salários e redução dos custos de treinamento para as organizações empregadoras, que contratam trabalhadores cujo treinamento eles mesmos pagaram.

\section{REFERÊNCIAS BIBLIOGRÁFICAS}

ALVES, Giovanni. Dimensões da Reestruturação Produtiva: ensaios de sociologia do trabalho. São Paulo: Editora Práxis, 2ª Ed., 2007.

ANTUNES, R. L. C. Os sentidos do trabalho: Ensaio sobre a afirmação e a negação do trabalho. São Paulo, Boitempo, 2003.

CASALLI, A. et. al. (org.). Empregabilidade e Educação: novos caminhos no mundo do trabalho. São Paulo: EDUC, 1997.

DIEESE. Dados do primeiro emprego no Brasil até o primeiro semestre de 2010. Disponível em: <http://www.turandot.dieese.org.br >. Acesso em 09 de setembro de 2010.

HELOANI, R. Organização do trabalho e Administração: uma visão multidisciplinar. São Paulo: Cortez, 1994. 
HIRATA, H.S. Os mundos do trabalho. In CASALLI, A. (et. al.) (org.). Empregabilidade e Educação: novos caminhos no mundo do trabalho. São Paulo: EDUC, 1997

MENEGASSO, M. E. As teorias administrativas e a empregabilidade vistas sob o enfoque da organização em aprendizagem. In: Revista de Ciências da Administração. Ano 1, no 2, agosto de 1999.

MÉSZÁROS, István. Para além do capital: rumo a uma teoria da transição. São Paulo: Boitempo, 2002.

. Desemprego e precarização. In: Vinculando, n. 07, 2005. Disponível em: <http://vinculando.org/brasil/desemprego.html >. Acesso em 01 out. 2010.

. O desafio e o fardo do tempo histórico: o socialismo do século XXI. Campinas: Boitempo, 2007.

MONTAÑO, Carlos. Das "lógicas do Estado" às "lógicas da sociedade civil": Estado e terceiro setor em questão. In: Revista Serviço Social e Sociedade. São Paulo: Cortez, № 59, ano XX, mar. 1999. pp. 47-79.

. Terceiro setor e questão social: crítica ao padrão emergente de intervenção social. São Paulo: Cortez, 2002.

NETTO, J. P. Capitalismo monopolista e Serviço Social. 2 Ed. São Paulo: Cortez, 1996.

POCHMAN, M. O emprego na globalização: a nova divisão do trabalho e os caminhos que o Brasil escolheu. São Paulo: Boitempo, 2009. 
OLIVEIRA, Eunice de. Toyotismo no Brasil: desencantamento da fábrica, envolvimento e resistência. São Paulo: Expressão Popular, 2004.

RIBAS, Clarilton C. Educação, Ética e Gênero no Toyotismo. in: AUED, Bernadete Wrublvski (Org.). Educação para o (Des)Emprego (ou quanto estar liberto da necessidade de emprego é um tormento). Petrópolis: Vozes, 1999.

SENAI: Almanaque das profissões. Disponível em: <http://www.senai.br/br/Almanaque/senai_vc_alm.aspx >. Acesso em: 16 out. 2008.

SHIROMA, E. Da competitividade para a empregabilidade: razões para o deslocamento do discurso. Texto suporte para a conferência apresentada pela pesquisadora no II Seminário de Educação Profissional realizado no CEFET PR, em 27/12/1998.

em: <http://www.gepeto.ced.ufsc.br/arquivos/dacompetitividade1.pdf >. Acesso em: 03 set. 2010.

TEIXEIRA, R. C. F. A passagem do "direito ao trabalho" para a "empregabilidade": privatização do espaço público através das políticas sociais de emprego na contemporaneidade. IN: UNIMONTES Científica. Vol 5, ano 1, 2003. Disponível em: <http://www.ruc.unimontes.br/index.php/unicientifica/article/viewArticle/80>. Acesso em 29 ago. 2010.

\footnotetext{
${ }^{1}$ Mestre em Ciências da Administração pela Universidade Federal de Santa Catarina (UFSC) e doutorando da Escola de Serviço Social da Universidade Federal do Rio de Janeiro (ESS/UFRJ). Email: gabrielmartinsrs@yahoo.com.br

2 "Com o aprofundamento da concorrência intercapitalista tem havido uma maior concentração e centralização do capital, seja nos setores produtivos, seja no setor bancário e financeiro, o que concede maior importância no papel das corporações transnacionais. Na realidade, conformam-se
} 
oligopólios mundiais, responsáveis pela dominação dos principais mercados, como é o caso do setor de computadores com apenas 10 empresas controlando $70 \%$ da produção, ou de 10 empresas que respondem por $82 \%$ da produção de automóveis, ou de 8 empresas que dominam $90 \%$ do processamento de dados, ou de 8 empresas que dominam $71 \%$ do setor petroquímico ou ainda de 7 empresas que respondem por 92\% do material de saúde" (POCHMAN, 2009, pp. 27-28).

${ }_{3}^{3}$ Programa governamental adotado, entre outros países, nos EUA e na Inglaterra que oferece a pessoas desempregadas assistência social, mas obriga, em contrapartida, os beneficiários a aceitar um emprego, geralmente mal remunerado, ou participar de treinamento profissional.

RECEBIDO EM: 05.07.2011

APROVADO EM: 16.07.2011 